\title{
TRABALHO E EDUCAÇÃO NO CONTEXTO DA REESTRUTURAÇÃO PRODUTIVA: O CANTEIRO ESCOLA
}

\section{WORK AND EDUCATION IN THE CONTEXT OF PRODUCTIVE RESTRUCTURING: THE JOBSITE SCHOOL}

\author{
Edson Caetano ${ }^{1}$ \\ Camila Emanuella Pereira Neves ${ }^{2}$
}

\section{RESUMO}

Este artigo faz uma reflexão sobre o binômio trabalho e educação a partir da reestruturação produtiva e dos programas educacionais, através de pesquisa realizada em uma construtora situada na cidade de Cuiabá, em 2010. A reestruturação produtiva no setor se inicia em 1983, quando as construtoras foram compelidas a promover alterações na organização do processo de trabalho. É dentro deste cenário que se inserem tanto a terceirização como a alfabetização. Procuramos compreender as mudanças e as implicações nas condições de trabalho, na organização e no conteúdo do trabalho decorrentes da adoção da terceirização. Analisamos também os projetos de alfabetização mantidos nos canteiros de obras, confrontando a visão expressa pelo setor administrativo da construtora e aquela expressa pelos trabalhadores acerca do significado, da importância e do papel atribuídos à educação.

Palavras-chave: Trabalho e Educação - Alfabetização de Adultos Reestruturação Produtiva.

\begin{abstract}
This Article is a reflection on the binomial work and education, from the productive restructuring and of educational programs, through research performed in a construction company located in the city of Cuiaba in 2010. The productive restructuring in the industry begins in 1983, where the builders were compelled to promote changes in the organization of the work process. It is within this scenario that fall under both the outsourcing, such as literacy. We tried to understand the changes and the implications on working conditions, on the organization and content of the work arising from the adoption of outsourcing. Also analyzed the projects of literacy kept us jobsites, confronting the vision expressed by administrative sector of construction company e by workers about the meaning, the importance and the role attributed to education.
\end{abstract}

Keywords: Work and Education - Adult Literacy - Productive Restructuring. 


\section{INTRODUÇÃO}

Este trabalho analisa as implicações da terceirização adotada por um número crescente de empresas de edificações habitacionais, visando ao aumento da competitividade. Analisa também os significados da alfabetização para o capital e para o trabalhador ${ }^{3}$.

Diante da crise que assolou este subsetor a partir de 1983, as empresas de edificações foram compelidas a promover alterações na organização do processo de trabalho, quer pelo colapso do Sistema Financeiro da Habitação, quer pelas novas exigências do mercado consumidor associadas à pressão dos operários da construção.

É neste cenário de instabilidade e de alterações no âmbito do processo de trabalho que se inserem tanto a estratégia da terceirização como a alfabetização e a qualificação profissional. Portanto, nosso foco de análise incidirá sobre estes dois tipos distintos de iniciativas, que correspondem a dois momentos diferentes na história recente da empresa pesquisada.

\section{PROCEDIMENTOS METODOLÓGICOS}

O estudo empírico baseou-se na análise de uma empresa de edificações habitacionais e de suas empresas terceirizadas. Os critérios para a escolha desta construtora foram: sua importância no cenário da construção habitacional (é uma construtora de grande porte, com altas taxas de lucratividade, apontada por empresas do subsetor como uma construtora moderna); a constatação de que em sua história recente foram implementadas experiências de alfabetização e de terceirização, possibilitando, assim, vislumbrar duas estratégias distintas numa mesma empresa.

No total foram gravadas 26 entrevistas, com duração média de uma hora cada. Destas, 7 foram realizadas na construtora pesquisada e estiveram direcionadas aos seguintes sujeitos: gerente de obras (1), gerente de suprimentos (1), gerente de recursos humanos (1), psicóloga (2), diretor (1) e pedagoga responsáveis pelo projeto Educar (1). Outras 13 entrevistas voltaram-se aos profissionais do canteiro de obras, contando com a participação de: mestre de obras (1), ajudante (4), auxiliar de almoxarifado (1), 
pedreiro (4), marceneiro (2), encanador (1). Realizamos, ainda, 4 entrevistas com alunos do curso de alfabetização mantido pelo sindicato da construção civil de Cuiabá: ajudante (2), pedreiro (2) e 2 entrevistas com diretores do sindicato dos trabalhadores da construção civil de Cuiabá. As entrevistas caracterizam-se como semi-estruturadas, o que possibilitou, por um lado, direcionarmos os depoimentos para aspectos tidos como importantes para 0 estudo e, por outro, propiciarmos liberdade para que os entrevistados abordassem temáticas que julgassem interessantes.

O teor das entrevistas realizadas visou a enfatizar os seguintes aspectos: a) junto aos representantes da gerência (terceirização, desemprego, reestruturação produtiva, concepção de educação); b) para os trabalhadores (importância da educação, condições de vida/trabalho, desemprego, perspectiva de vida); c) para os dirigentes sindicais (desemprego, terceirização, educação).

\section{EDUCAR PARA O AMANHÃ: UM PROJETO DE ALFABETIZAÇÃO}

A empresa pesquisada foi fundada em 1973, em Cuiabá, tendo como atividade principal a construção de edificações na região metropolitana desta cidade. A mesma é considerada desde os primeiros anos de 1980 como uma das empresas líderes do subsetor. O número total de operários da empresa é 230 (base: julho/2010) distribuídos da seguinte forma: 193 operários na produção e 37 no setor administrativo. No período de realização da pesquisa (ano 2010), 9 obras estavam sendo edificadas, possibilitando a produção média anual de aproximadamente $75.000 \mathrm{~m}^{2}$ de construção.

Em 1990 a empresa pesquisada criou o 'Projeto Educar para o Amanhã' destinado à alfabetização dos trabalhadores mantidos por ela nos canteiros de obras. O momento de criação do programa de alfabetização é marcado, segundo Barone e Letelier (1995), pela retração da migração para os grandes centros urbanos e, assim, por uma queda na oferta de força de trabalho. Em tal conjuntura, as empresas de edificações são compelidas a disputar trabalhadores com setores produtivos que oferecem melhores condições de trabalho.

Do ponto de vista conjuntural, o momento de criação dos projetos de 
alfabetização é marcado pela articulação entre a crise econômica e a crescente exigência do mercado consumidor do produto moradia. Para garantir maior competitividade, as empresas de edificações intensificam esforços visando ao "aumento da produtividade, a diminuição do desperdício de materiais, a diminuição dos acidentes de trabalho e a melhoria na qualidade do produto" (BARONE; LETELIER, 1995, p. 447).

A alfabetização, segundo a empresa pesquisada, cumpre um papel essencialmente instrumental, por ser concebida como um elemento capaz de garantir o incremento da produtividade e, portanto, da lucratividade.

A empresa tinha uma vontade grande de que a questão da qualidade fosse trabalhada a partir da oportunidade da escola. Quer dizer, que o trabalhador tivesse crítica em cima daquele trabalho que ele estava fazendo, então a escola foi um investimento da empresa nesse sentido, na busca dessa qualidade (Sandra, psicóloga). ${ }^{4}$

Outro aspecto viabilizado através da educação e extremamente valorizado, segundo a construtora, é o suposto aumento da responsabilidade que o trabalhador alfabetizado demonstra ter durante a execução de seu respectivo ofício:

Com a alfabetização, o cara passa a saber que se ele faltar vai acarretar mais trabalho para o outro. Ele passa a pensar um pouco mais em grupo, ele tem uma consciência a nível de acidentes, ele tem uma consciência a nível de desperdício, retrabalho (Ana Luiza, responsável pelo Projeto Educar).

Entretanto, cumpre destacar que, em sua maioria, as condições encontradas pelos trabalhadores diariamente nos canteiros de obras não apresentam alterações importantes. Estes permanecem caracterizados como locais de trabalho marcados pela sujeira e desorganização, pelo barulho e pelo perigo. Isso equivale a dizer que o trabalhador modificou-se qualitativamente a partir da alfabetização, principalmente pelo resgate de sua auto-estima; mas o canteiro de obras não, permanecendo então um descompasso entre o perfil do trabalhador e seu local de trabalho.

Ainda em relação à valorização do processo de escolarização detectado nas falas de parte da gerência dos canteiros de obras, é enfatizado o papel desempenhado pelo sistema educacional com referência ao adestramento, no sentido de moldar o trabalhador segundo os padrões desejados pelo capital (FRIGOTTO, 1999). 
O principal da escola é dar consciência e disciplina ao operário. A primeira coisa é que ele tem que ser disciplinado, não pode ser bocudo, respondão, tem que ser uma pessoa fácil de lidar. Tudo que você manda ele fazer, ele está pronto para fazer (Orlando, mestre de obras, grifos nossos).

Ressaltamos que, embora parte da gerência dos canteiros de obras mantidos pela empresa pesquisada pense a educação como um meio de adestrar o trabalhador, isto não implica que a escola cumpra efetivamente tal papel. Este descompasso entre o papel que o capital deseja que a escola cumpra e a realidade na sala de aula explica-se, como bem assinalam Carnoy e Levin (1993, p. 70), por ser a educação "ao mesmo tempo, o resultado de contradições e origem de novas contradições. É uma área de conflitos a respeito da produção de conhecimentos, ideologia e emprego (...)".

A escola deve transformar esse trabalhador num cidadão. Então é isso que eu chamo ser cidadão: é a pessoa ouvir, tentar criticar, emitir a sua opinião, coisa que eles não fazem (Ana Luiza, responsável pelo Projeto Educar).

O depoimento acima expressa a dificuldade que a construtora possui em controlar não somente os conteúdos e a postura dos professores, mas, sobretudo, a dinâmica das aulas. Dito de outra maneira, o dia-a-dia escolar é construído/reconstruído pelos atores envolvidos no processo de aprendizagem (professor, aluno) e inexiste planejamento/intervenção pedagógica capaz de prever e ou controlar totalmente o inesperado característico da sala de aula.

\section{ALFABETIZAÇÃO NOS CANTEIROS DE OBRAS: POSSÍVEIS SIGNIFICADOS}

Os trabalhadores/alunos que passaram e passam pelos canteiros de obras/escolas procurando aprender a ler e escrever apresentam em comum não só a origem rural (principalmente da região norte e nordeste do país), mas principalmente o semblante cansado de quem teve uma história de vida pautada pela pobreza e um cotidiano de trabalho extremamente penoso.

Eu trabalhava na lavoura na Bahia junto com a minha mãe porque o meu pai, antes de eu nascer, ele morreu. Aí, fiquei eu com a minha mãe e meus dois avôs. Nisso, eu comecei a estudar, acho que eu estudei uns seis meses, aí já comecei a trabalhar porque eu já tinha 
uma forcinha e nós tudo era pobrezinho. Aí, larguei a escola para trabalhar para ajudar minha família (Francisco, faxineiro).

A totalidade dos trabalhadores que participaram do 'Projeto Educar' é formada por homens com idade entre 18 e 50 anos, analfabetos ou semianalfabetos, moradores da periferia de Cuiabá, trabalhadores sem qualificação anterior e que obtiveram na construção civil a única oportunidade de emprego na cidade. As dificuldades enfrentadas diariamente por estes trabalhadores decorrem de várias situações. Em primeiro lugar, a maioria deles acorda três horas antes do início da jornada de trabalho e retorna às suas casas no final do dia, entre três e quatro horas após o término das aulas ${ }^{5}$. Em segundo lugar, diferentemente de outros setores produtivos, o subsetor de edificações habitacionais exige que o trabalhador execute seu respectivo ofício sob as intempéries do tempo. Por último, e não menos importante, encontra-se um traço marcante do trabalho realizado no canteiro de obras, qual seja: o trabalho concretiza-se pelo dispêndio da força física do trabalhador.

Apesar do cansaço, do desânimo, da falta de perspectivas, estes trabalhadores, muitos com idade acima dos 50 anos, superam-se e procuram habituar-se ao manuseio de um instrumento que não requer força, mas sim habilidade. Este instrumento é o lápis. Nas duas horas de aula obtidas por dia, a força física não se faz necessária e quando observamos os alunos sentados tentando desenhar as primeiras letras, quase não enxergamos trabalhadores fortes e calejados, mas sim crianças tentando, errando e, por fim, com o olhar brilhante, conseguindo escrever alguma palavra.

O que mata na construção é a canseira. A gente tem que gostar mesmo de estudar, tem que ter vontade porque geralmente no serviço de obras chega à tarde, o cara ta num bagaço danado: é frio, é chuva, é sol, é vento (Francisco, pedreiro).

A leitura aparece para os alunos do projeto como algo que alterou qualitativamente suas vidas não apenas no âmbito do trabalho, mas também no cotidiano. A maior parte dos trabalhadores valoriza a leitura face aos benefícios alcançados no âmbito da vida cotidiana, tal como a leitura de jornal, da carta da família e do letreiro do ônibus.

Aqui eu aprendi a ler um pouco, agora eu não tenho mais dúvida em ir em tal lugar porque eu já sei ler o nome de ônibus, estação de 
metrô. Para onde eu for agora eu não fico mais perguntando a ninguém porque agora eu vou sozinho (José Carlos, marceneiro).

O domínio da leitura possibilita ao trabalhador locomover-se sozinho por meio de transportes coletivos, sem que tenha o constrangimento de perguntar constantemente às pessoas em volta sobre o itinerário pretendido. Com isso, o grau de autonomia e liberdade do trabalhador aumenta e consequentemente a sua auto-estima, pois pior que ser analfabeto é explicitar diariamente tal condição a desconhecidos.

O mais importante para mim é saber ler, a minha irmã sempre compra jornal então eu posso pegar, posso ler algumas coisas no jornal que nem negócio de esportes que eu gosto demais. (Orlando, ajudante).

Nos depoimentos, percebe-se que a importância atribuída à leitura é superior àquela atribuída ao domínio da escrita. A esse respeito, Barone e Letelier (1995, p.465) salientam que, "no viver cotidiano, em geral, as necessidades de leitura sobrepõem-se às necessidades de escrita - isto faz com que as referências dos trabalhadores direcionem-se, com maior freqüência, à primeira destas habilidades".

Os conhecimentos obtidos através da escolarização são considerados importantes em várias situações da vida do trabalhador, porém, o mesmo não ocorre em relação à execução do trabalho no canteiro de obras, porque não modifica o conteúdo do trabalho e as relações de poder no canteiro.

A gente não saber ler e escrever na parte de pedreiro não atrapalha porque o pedreiro não precisa ter muito estudo. A parte de cálculo, essas coisa aí já é para o engenheiro, mestre de obras, quer dizer, isso aí nem para o encarregado já não faz tanta falta (Paulo, pedreiro de alvenaria).

A totalidade dos depoimentos obtidos junto aos trabalhadores dos canteiros de obras expressa a fragilidade de vínculos constituídos entre escolarização e execução das tarefas, independentemente do ofício; ou seja: a execução correta do trabalho não requer, necessariamente, um trabalhador com determinado nível educacional, mas sim que o mesmo possua experiência profissional adquirida no próprio local de trabalho. Em decorrência desta percepção, para os trabalhadores entrevistados, a escolarização é tida como o único instrumento capaz de concretizar o sonho de sair do canteiro de obras e 
trabalhar em outro setor produtivo, que ofereça melhores condições de trabalho.

Se eu tivesse estudado, poderia ter um serviço melhor, eu jamais ia querer trabalhar aqui e é claro que eu quero sair. É aquilo que eu falo: hoje em dia o estudo não é tudo, mas a maior arma minha e eu acho que para o pobre é um estudo (Nelson, ajudante).

O desemprego passa a ser compreendido pelo trabalhador que passou pela escola como um fenômeno que independe da vontade do trabalhador. Desta maneira, a escola estimula a criticidade no aluno/trabalhador, fornecendo-Ihe ferramentas que the possibilite compreender o mundo em que vive 6 .

É óbvio que o estudo me ajuda e vai me ajudar mesmo se eu tiver desempregado. Mesmo assim, ele vai tá me ajudando porque pelo menos eu vou ter a certeza que eu estou procurando serviço não por causa de mim, mas pela situação do país (Marcos, ajudante).

Com base no depoimento precedente, pode-se depreender que a importância da escolarização não está na possível superação do desemprego, mas sim na compreensão da problemática do desemprego enquanto um problema social e não individual.

A partir da análise dos depoimentos fornecidos pelos trabalhadores acerca da importância da escola em suas vidas, concluímos que a alfabetização significou para os mesmos o reforço à sua auto-estima, melhor convívio no local de trabalho, domínio do código escrito e, fundamentalmente, a base através da qual foram ampliadas as noções de criticidade e cidadania que Ihes possibilitam o sentimento de pertencimento a uma dada sociedade.

$\mathrm{Na}$ perspectiva da construtora pesquisada, a educação é uma ferramenta capaz de melhorar o desempenho do trabalhador durante a execução de seus ofícios. A alfabetização emerge também como necessidade de adequar o nível escolar a novos processos construtivos, que demandam um trabalhador capaz de ler manuais de procedimento. Todavia, conforme enfatizamos acima, para o trabalhador a escolarização não tem relação direta com a execução do trabalho nos canteiros de obras, pois os "segredos" dos ofícios são apreendidos através da observação junto ao oficial e demandam prática e não leitura ou escrita. 


\title{
A EMPRESA ESTUDADA NO CONTEXTO DA TERCEIRIZAÇÃO
}

\begin{abstract}
A partir de 1990, intensifica-se o processo denominado 'reestruturação produtiva', visto que a articulação entre o aumento da produtividade e a redução de custos é considerada a alternativa à subsistência das empresas num cenário doravante marcado pelo acirramento da concorrência entre as mesmas. A concorrência que até então permanecia, em certa medida, circunscrita aos mercados nacionais, não mais observará as fronteiras regionais, ou seja, a produção, a distribuição e o consumo de bens mundializam-se ${ }^{8}$.
\end{abstract}

Em 2010, a empresa havia terceirizado todas as etapas do processo no segmento de edificações habitacionais (através da padronização e estandardização do projeto) e nos demais segmentos este índice atingia $90 \%$ das etapas. A terceirização e as inovações tecnológicas evidenciam um cenário marcado pela crescente precarização das condições de trabalho. A referida degradação das condições de trabalho pressupõe a flexibilização progressiva do mercado de trabalho através das seguintes iniciativas:

\begin{abstract}
flexibilização da organização do trabalho e da produção (polivalência, exteriorização etc.); flexibilização dos tempos de trabalho (diversificação, variabilidade, mobilidade etc.); flexibilização das formas de emprego (redução de proteções contra as garantias de trabalho, alargamento de postos precários); flexibilização do custo salarial direto (posto em causa através da indexação dos salários sobre os preços e de reduções legais) e indireto (reformas de indenização do desemprego) (FREYSSINET, 1997, p. 3).
\end{abstract}

A subcontratação, segundo o setor de engenharia da empresa pesquisada, é a única estratégia capaz de assegurar a manutenção das construtoras no mercado, tida então como algo inevitável.

Hoje eu acredito que a palavra construtora deva acabar, aquela empresa piramidal, verticalizada com diretor, gerente, não sei o que, área de suprimentos, área de financeira... É uma questão de sobrevivência (Alcides, engenheiro).

A propósito da estruturação do mercado de trabalho na década de 90, Harvey (1992, p. 145-146) afirma que: 
a subcontratação organizada abre oportunidades para a formação de pequenos negócios e, em alguns casos, permite que sistemas antigos de trabalho doméstico, artesanal, familiar (patriarcal) e paternalistas ('padrinhos', 'patronos' e até estruturas semelhantes à da máfia) revivam e floresçam, mas agora como peças centrais, e não apêndices do sistema produtivo.

A crescente terceirização de etapas do processo construtivo nos canteiros mantidos pela empresa faz com que parte da gerência vislumbre o seguinte cenário para a construtora num futuro não muito distante:

eu imagino que até eu vou ser acionista desta empresa, eu vou ser um prestador de serviços para a empresa. A empresa num futuro bem próximo vai ser uma marca com prestadores de serviços para esta entidade. (...) Para você entender melhor é o seguinte: uma Nike, ela não faz tênis, ela não faz nada, ela só tem a marca; uma Beneton não faz nada; uma Microsoft também, ela não faz nada, ao contrário, ela mantém uns carinhas pensando para ela lá, só aquele grupo fica pensando lá e ela tem um faturamento astronômico. E esta empresa aqui atuando enquanto empresa-mãe fazendo esses negócios e articulando esses negócios e tudo ${ }^{9}$ (Alcides, engenheiro).

Passados seis meses da obtenção do depoimento acima, constatase que certas afirmações ali presentes de fato materializaram-se, como por exemplo, a subcontratação crescente de etapas da obra e a redução de $68,9 \%$ na força de trabalho empregada na produção, enquanto que no setor administrativo a redução atingiu $72,6 \%$. Por outro lado, o engenheiro que forneceu o depoimento não se tornou acionista ou prestador de serviços da construtora - como pressupunha - e mais, foi demitido juntamente com outros trabalhadores em outubro de 2010.

\section{A PRECARIZAÇÃO ABSOLUTA}

Grande parte das análises que priorizam a problematização acerca dos efeitos da terceirização sobre as condições de trabalho indica a crescente precarização e aumento do desemprego que atingem o conjunto dos trabalhadores em diferentes níveis: diminuição dos benefícios sociais; degradação salarial; aumento do desemprego; ausência de equipamento de proteção/falta de segurança/insalubridade; trabalho menos qualificado; trabalho sem registro; desorganização sindical pelo esfacelamento e fragmentação do coletivo de trabalhadores e jornada mais extensa. 
O que singulariza a subcontratação no Brasil é, em primeiro lugar, o seu grau de alcance, por atingir atualmente empresas de edificações de grande porte e que, historicamente, construíram uma trajetória num sentido diverso (como por exemplo, a construtora pesquisada) e, em segundo lugar, situa-se na conjugação nefasta para os trabalhadores entre subcontratação, desemprego e desregulamentação de direitos trabalhistas. A redução do número de postos de trabalho, motivada dentre outros fatores pela implementação da terceirização, é a conseqüência mais visível e prejudicial aos trabalhadores.

A situação de desemprego no subsetor apresenta contornos extremamente graves, pois o período de procura por um novo emprego é longo, o desemprego atinge principalmente os trabalhadores desqualificados e/ ou com idade acima dos 35 anos e estes desempregados não possuem qualificação profissional anterior ou escolarização que Ihes possibilite migrar para outros setores produtivos.

Outro aspecto referente ao desemprego diz respeito à sua incidência/predominância sobre determinado tipo de trabalhador. No caso do subsetor analisado, o desemprego atinge com maior intensidade os trabalhadores não qualificados.

\footnotetext{
Infelizmente, o não qualificado cada vez mais vai sobrando no mercado. Então, esse cara que a gente chama de servente, que é aquele que ajuda os outros, está saindo do mercado porque as coisas vão sendo mecanizadas. Várias coisas que se faziam na obra, que eram feitas manualmente por um indivíduo vai sendo extinta. (Luiz Carlos, engenheiro)
}

A difusão da subcontratação articulada à utilização de novos equipamentos e ferramentas de trabalho, bem como novos materiais, reduzem drasticamente as atividades anteriormente desenvolvidas pelos ajudantes e, por conseguinte, reduz-se o número dos mesmos nos canteiros de obras. Com isso, dá-se o fechamento da porta de entrada para o mercado de trabalho de um enorme contingente de operários migrantes, sem qualificação e analfabetos.

De acordo com o depoimento de um engenheiro da empresa pesquisada, o desemprego do trabalhador sem qualificação é mais dramático: 
Você não pode deixar de levar em conta que esse indivíduo não qualificado que está diminuindo, não é só o emprego que ele está perdendo. Esse cara, ele mora na obra e se alimenta nesse local de trabalho. Então, cada vez que ele perde o emprego, ele não perdeu só o emprego, ele perdeu também o teto e a comida, é um indivíduo que não tem onde morar e se alimentar, além de não ter mais salário. (Moisés, engenheiro)

Segundo a direção do Sindicato, as construtoras terceirizadas não cumprem a Consolidação das Leis do Trabalho (CLT), chegando ao ponto de não pagarem sequer os dias trabalhados aos operários.

Os trabalhadores das subcontratadas trabalham até sem salários, isso nós vemos todo o dia. Tem operário que chega a trabalhar um, dois ou três meses sem receber um tostão. Aí você aciona os órgãos que se dizem competentes para cobrar isso das empresas e aí a coisa se enrola por muito tempo. Nisso, a empresa troca de nome e CGC, pedem falência o dia que quer e o coitado do trabalhador sem receber (Alcides, diretor do sindicato da construção de Cuiabá).

Referindo-se a este tipo de relação, Bresciani (1997, p. 200) ressalta

que:

$\mathrm{Na}$ imensa maioria dos casos, a chamada terceirização à brasileira tem sido apenas mais um expediente para reduzir custos a qualquer preço, em que especialização e qualidade são retórica vazia, e a degradação do trabalho, do trabalhador, e também do produto, se renovam como meios espúrios de competitividade empresarial.

Outra prática crescente a partir da subcontratação é a contratação do trabalhador sem registro em carteira, portanto, sem direitos vinculados ao trabalho. O temor em adquirir a condição (real) de desempregado, que traz consigo a recusa em submeter-se a privações das mais diversas, acaba por induzir o trabalhador a aceitar esse tipo de contratação.

Nós vamos encontrar um índice grande de trabalhador sem carteira assinada e esse é o ponto mais explorador que existe. Isso acontece nas terceirizadas, ou dos pequenos construtores, ou dos gatos e isso nós conseguimos detectar principalmente quando tem morte na obra. Aí nós pegamos muitos trabalhadores sem registro e que acabam se acidentando e morrendo, aí é a hora da correria pra registrar o camarada depois de morto, entendeu? (Alcides, diretor do sindicato da construção de Cuiabá).

O depoimento acima evidencia o uso predatório da força de trabalho no setor da construção civil, posto que a empresa subcontratada procura legalizar a situação do trabalhador já morto, como se a premissa para a 
existência formal e legal do trabalhador do canteiro de obras fosse a inexistência.

Cabe enfatizarmos que a adoção da terceirização, segundo a empresa contratante, contribuiu para o aumento da competitividade da mesma, pois possibilitou fundamentalmente a diminuição de custos. Todavia, na ótica de trabalhadores e sindicalistas, a terceirização é sinônimo de precarização das condições de trabalho, pois estas, quando oferecidas pelas construtoras de médio e pequeno porte (terceirizadas), são piores do que as encontradas nas construtoras de grande porte (contratantes).

\section{CONSIDERAÇÕES FINAIS}

Neste trabalho foram analisados os condicionantes e as implicações decorrentes da implementação do processo de terceirização em uma construtora localizada em Cuiabá. A terceirização tem sido utilizada por um número crescente de empresas do subsetor de edificações habitacionais enquanto estratégia de racionalização do trabalho.

A trajetória da construtora pesquisada informa-nos que a busca por maior eficiência através da articulação entre o aumento da produtividade e a minimização de custos viabilizou-se pela escolha de diferentes estratégias de racionalização do processo de trabalho, que procuravam responder a determinadas conjunturas. Diante de uma conjuntura marcada pelo acirramento concorrencial, a construtora substituiu a política de valorização do trabalhador pela terceirização.

O empreendedor terceirizado ou a empresa subcontratada é um trabalhador por conta própria ou até mesmo um empregador sob o controle da empresa contratante. Dessa forma, reelabora-se o conceito de trabalhador coletivo, ampliando-o, pois se rompem os limites da empresa através da incorporação de outros trabalhadores vinculados a diferentes empresas no mesmo processo produtivo.

$\mathrm{Na}$ realidade, a terceirização propicia diminuição de custos para a empresa contratante porque o valor da remuneração concedida à empresa contratada é inferior ao despendido com trabalhadores próprios. A empresa terceirizada, apesar das queixas, mantém um volume de serviços superior ao 
que detinha anteriormente e obtém redução nos custos de manutenção de seus trabalhadores através da intensificação da precarização das condições de trabalho nos canteiros de obras (burla à legislação trabalhista, pagamento por tarefa, descompromisso com o fornecimento de equipamento e cursos de segurança do trabalho, etc).

Do exposto anteriormente, concluímos que na terceirização, subcontratação, parceria, cooperação ou seja qual for a denominação dada a esse tipo de estratégia de flexibilização, a lucratividade auferida pelas empresas resulta da intensificação da exploração da força de trabalho ${ }^{10}$.

A escolarização não propiciou ascensão profissional e tampouco melhoria salarial ao trabalhador do canteiro de obras; ademais, tem-se que o "saber ler e escrever" alimenta o sonho deste em um dia deixar de trabalhar como pedreiro. Outro fato que merece destaque: embora a fala de alguns dos trabalhadores entrevistados aponte para a existência de vínculos entre educação e trabalho, na visão majoritária dos mesmos a alfabetização é posta como um mecanismo que alterou positivamente suas vidas fora da esfera da produção. Por último, mas de fundamental importância, está a contribuição da escolarização no sentido de desenvolver a criticidade e a cidadania dos trabalhadores, municiando-os com conhecimentos que lhes possibilitem compreender o mundo em que vivem e possivelmente participarem de maneira ativa na construção de uma sociedade mais justa e solidária.

\section{REFERÊNCIAS}

BARONE, Rosa Elisa \& LETELIER, Maria Eugênia. "Canteiro escola": uma resposta da indústria da construção no contexto produtivo atual -. In: Educação \& Sociedade, n.ํ52, Campinas: Papirus, dezembro/1995.

BRESCIANI, Luís Paulo. Os desejos e o limite: reestruturação industrial e ação sindical no complexo automotivo brasileiro. In: LEITE, Márcia de Paula (org.). 0 trabalho em movimento: reestruturação produtiva e sindicatos no Brasil. São Paulo: Papirus, 1997.

CARNOY, Martin \& LEVIN, Henry M. Escola e trabalho no estado capitalista. São Paulo: Cortez, 1993.

CATTANI, Antonio David. Trabalho e tecnologia: dicionário crítico. Petrópolis: Vozes, 1997. 
CHESNAIS, François. A mundialização do capital. São Paulo, Xamã, 1996.

ENGUITA, Mariano Fernández. A face oculta da escola: educação e trabalho no capitalismo. Porto Alegre, Artes Médicas, 1989.

FREYSSINET, Jacques. Le rôle du chômage de masse dans la flexibilisation de l'emploi. In: APPAY, Béatrice \& THÉBAUD-MONY, Annie. Précarisation sociale, travail et santé. Paris, Iresco, 1997.

FRIGOTTO, Gaudêncio. Educação, crise do trabalho assalariado e do desenvolvimento: teorias em conflito. In: FRIGOTTO, Gaudêncio (org.), Educação e crise do trabalho: perspectivas de final de século. Petrópolis: Vozes, 1999.

HARVEY, David. Condição pós-moderna: uma pesquisa sobre as origens da mudança cultural. São Paulo: Edições Loyola, 1992.

MARX, Karl. O capital: crítica da economia política. São Paulo: Difel, Livro 1, Volume 1, 1982.

SINGER, Paul. A crise das relações de trabalho. In: NABUCO, Maria Regina \& NETO, Antônio Carvalho (orgs.). Relações de trabalho contemporâneas. Belo Horizonte: Sociedade Editora e Gráfica de Ação Comunitária, 1999.

\footnotetext{
${ }^{1}$ Professor Adjunto da Universidade Federal de Mato Grosso (UFMT/Cuiabá). Doutor e Mestre em Educação pela Universidade Estadual de Campinas (UNICAMP) e Graduado em Ciências Sociais pela Pontifícia Universidade Católica de Campinas (PUCCAMP). E-mail: caetanoedson@hotmail.com

2 Doutoranda em Educação pela Universidade Federal de Mato Grosso (UFMT); Mestre em Educação pela Universidade Federal de Mato Grosso (UFMT) e Graduada em Pedagogia pela Universidade Federal de Mato Grosso (UFMT). E-mail: camilaemanuella@hotmail.com

${ }^{3}$ Este artigo é resultado de uma releitura do relatório final de Projeto de Pesquisa sobre Educação de Jovens e Adultos Trabalhadores. A pesquisa de campo foi realizada em uma empresa de edificações habitacionais situada em Cuiabá no ano de 2010.

${ }^{4}$ Os nomes dos entrevistados são fictícios (o que assegura o anonimato dos mesmos).

${ }^{5}$ É interessante ressaltar que de tempos em tempos o trabalhador desloca-se para um canteiro de obras numa região diferente, implicando um interminável acostumar-se a itinerários diferentes e, por conseguinte, a ônibus com horários diferenciados.

${ }^{6}$ Enguita (1989, p. 218) entende que "embora possamos caracterizar a escola, em geral, como uma instituição que busca moldar as pessoas, não é possível ignorar que estas não são simples matérias primas ou produtos semitransformados dos quais se pode fazer qualquer coisa, como sugere a metáfora da tábula rasa. Trata-se, pelo contrário de seres humanos, dotados de inteligência e vontade, cujos desejos, preferências, aversões, expectativas, experiências, etc., se traduzem em respostas individuais e grupais aos imperativos da instituição, com o resultado final de que os resultados obtidos por esta não podem chegar jamais a coincidir com seus desígnios iniciais".
} 
7 "A reestruturação produtiva e industrial consiste em um processo que compatibiliza mudanças institucionais e organizacionais nas relações de produção e de trabalho, bem como redefinição de papéis dos estados nacionais e das instituições financeiras, visando a atender às necessidades de garantia de lucratividade". (CATTANI, 1997, p. 202).

8 'O termo de origem francesa 'mundialização' (mondialisation) encontrou dificuldades para se impor, não apenas em organizações internacionais, mesmo que supostamente bilíngües, como a OCDE, mas também no discurso econômico e político francês. Isso deve-se, claro, ao fato de que o inglês é o veículo linguístico por excelência do capitalismo e que os altos executivos dos grupos franceses estão entupidos dos conceitos e do vocabulário em voga nas business schools. Mas também, com certeza, ao fato de que o termo 'mundialização' tem o defeito de diminuir, pelo menos um pouco, a falta de nitidez conceitual dos termos 'global' $e$ 'globalização'. A palavra 'mundial' permite introduzir, com muito mais força do que o termo 'global', a idéia de que, se a economia se mundializou, seria importante construir depressa instituições políticas mundiais capazes de dominar o seu movimento. Ora, isso é o que as forças que atualmente regem os destinos do mundo não querem de jeito nenhum. Entre os países do Grupo dos Sete - EUA, Canadá, Japão, França, Alemanha, Reino Unido, Itália - os mais fortes julgam ainda poder cavalgar vantajosamente as forças econômicas e financeiras que a liberalização desencadeou, enquanto os demais estão paralisados ao tomarem consciência, por um lado, de sua perda de importância e, por outro, do caminho que vão ter de percorrer para adaptar-se". (CHESNAIS, 1996, p. 24).

9 "O oligopólio, a grande empresa capitalista clássica, multinacional, transnacional, isto é, empresas existentes em centenas de países, empregando centenas de milhares de pessoas, cujas vendas anuais superam o PIB de um grande número de países pequenos, estão se descentralizando, estão ficando menores, porém criando ao seu redor uma rede de pequenas e médias empresas filiadas, subcontratadas, algumas vezes, com posse cruzada de ações. Isso é uma novidade. Dentro disto surge o franqueamento. Estão surgindo grandes redes de empresas, em que o núcleo é comparativamente pequeno. Por exemplo, a Benetton, um caso interessantíssimo, é uma empresa que, basicamente, desenvolve modelos de confecção e subcontrata a fabricação dessas roupas com dezenas de empresas outras, e, finalmente vende essas roupas no mundo inteiro." SINGER (1999, p. 34-35).

10 "Antes de tudo, o motivo que impele e o objetivo que determina o processo de produção capitalista é a maior expansão possível do próprio capital, isto é, a maior produção possível de mais valia, portanto, a maior exploração possível da força de trabalho" (MARX, 1982, p. 380).

RECEBIDO EM: agosto/2013

APROVADO EM: setembro/2013 